\title{
In vitro and in vivo activity of R- and S- praziquantel enantiomers and the main human metabolite trans-4-hydroxy- praziquantel against Schistosoma haematobium
}

Jana Kovač $\check{c}^{1,2}$, Mireille Vargas ${ }^{1,2}$ and Jennifer Keiser ${ }^{1,2^{*}}$

\begin{abstract}
Background: Praziquantel (PZQ) is the mainstay of schistosomiasis control and has been successfully used for decades. However, its mechanism of action is not fully understood. While the majority of studies have been conducted on Schistosoma mansoni, it is not known which enantiomer, R- or S-praziquantel (R-/S-PZQ), is responsible for the activity on Schistosoma haematobium.
\end{abstract}

Methods: In vitro and in vivo studies were conducted to evaluate the activity of R- and S-PZQ, racemic PZQ and the main human metabolite, namely trans-4-OH-PZQ, on S. haematobium. IC $\mathrm{C}_{50}$ values on adult S. haematobium were determined in vitro. Dose-response relationship studies were performed in golden Syrian hamsters, harbouring a chronic S. haematobium infection.

Results: R-PZQ displayed the highest activity against adult worms in vitro, revealing an $\mathrm{IC}_{50}$ of $0.007 \mu \mathrm{g} / \mathrm{ml}$ at $4 \mathrm{~h}$ and $0.01 \mu \mathrm{g} / \mathrm{ml}$ at $72 \mathrm{~h}$. In contrast, S-PZQ was $501 \times$ less active (eudysmic ratio at $4 \mathrm{~h}$ ), with an $I C_{50}$ of 3.51 and $3.40 \mu \mathrm{g} / \mathrm{ml}$ (4 and $72 \mathrm{~h}$, respectively). Racemic PZQ and trans-4-OH-PZQ resulted in an $\mathrm{IC}_{50}$ of $0.03 \mu \mathrm{g} / \mathrm{ml}$ and $1.47 \mu \mathrm{g} / \mathrm{ml}$ both at 4 and $72 \mathrm{~h}$, respectively. In vivo, R-PZQ was the most potent drug with worm burden reductions (WBRs) of 98.5, 75.6 and 73.3\% at 125.0, 62.5 and $31.0 \mathrm{mg} / \mathrm{kg}$, respectively. A single oral dose of $250.0 \mathrm{mg} / \mathrm{kg}$ PZQ resulted in a WBR of 99.3\%. S-PZQ was highly active in vivo at 250.0 and $500.0 \mathrm{mg} / \mathrm{kg}$ with WBRs of 83.0 and $94.1 \%$, respectively. The lowest tested dose of S-PZQ, $125.0 \mathrm{mg} / \mathrm{kg}$, showed moderate activity (WBR of 46.7\%). The calculated $\mathrm{ED}_{50}$ for

R- and S-PZQ were 24.7 and $127.6 \mathrm{mg} / \mathrm{kg}$, respectively, with a corresponding eudysmic ratio of 5.17 .

Conclusion: Our data support the theory of R-PZQ driving the antischistosomal activity. Interestingly, also S-PZQ proved to possess a significant activity towards S. haematobium, particularly in vivo.

Keywords: Praziquantel, Schistosoma haematobium, In vivo, In vitro

\footnotetext{
* Correspondence: jennifer.keiser@swisstph.ch

'Department of Medical Parasitology and Infection Biology, Swiss Tropical and Public Health Institute, Basel, Switzerland

¿University of Basel, Basel, Switzerland
} 


\section{Background}

Schistosomiasis is one of the prominent neglected tropical diseases (NTDs), caused by blood-dwelling flukes of the genus Schistosoma. It is affecting over 230 millions of people around the world, mostly concentrated in poor, tropical and subtropical areas [1-3].

Intestinal schistosomiasis, caused by $S$. mansoni and S. japonicum, manifests with abdominal symptoms (e.g. blood in stool, abdominal discomfort, diarrhoea) and can lead to liver failure $[4,5]$, while $S$. haematobium causes urinary schistosomiasis, triggering bladder pathology, often resulting in bladder cancer $[4,6]$. In addition, schistosomiasis influences the course and outcome of pregnancy and affects child's intellectual and physiological development $[7,8]$.

Praziquantel (PZQ) is the only effective drug available against schistosomiasis and has been successfully in use for decades [4, 6, 9-13]. Originating from veterinary medicine and repurposed for human use, it has been thoroughly studied; however, knowledge regarding the mechanism of action is scarce $[9,11]$. PZQ is a racemic compound consisting of two enantiomers, R- and SPZQ $[9,11]$. While there have been some in vitro and in vivo studies on the activity of PZQ, they mostly studied the racemic drug [14-20]. In the few studies, which explored the activity of either R- or S-PZQ, the reported findings vary. Nevertheless, most studies reported greater activity of R-PZQ over S-PZQ [21-24]. Staudt et al. [24] suggested that the main metabolite, R-trans-4hydroxy-praziquantel (trans-4-OH-PZQ), also possesses a high antischistosomal activity on $S$. mansoni. A similar finding was reported by Xiao et al. [25] for S. japonicum.

It is worth highlighting that the above-mentioned studies, testing the enantiomeric activity of R- and S-PZQ, were conducted using exclusively $S$. mansoni and S. japonicum. Schistosoma haematobium remains largely unexplored, regardless of the fact that it is responsible for the largest number of infections [26]. One of the many reasons of negligence might be the life-cycle of the parasite, which is difficult to maintain in laboratory conditions [27-29]. However, drug activity should be carefully elucidated on S. haematobium as well, since there is evidence that the activity of drugs, e.g. PZQ, oxamniquine or metrifonate, differs between species of the parasite $[18,30]$.

In this study, the activity of both PZQ enantiomers, Rand S-PZQ, as well as the racemic drug and the main metabolite (trans-4-OH-PZQ) was assessed on S. haematobium. The activity of all entities was tested in vitro on adult worms and the results were reported as $\mathrm{IC}_{50}$ values. The $S$. haematobium hamster model was used for testing different dosages of R-PZQ and S-PZQ compared with racemic $\mathrm{PZQ}$ in vivo. $\mathrm{ED}_{50}$ values were reported and worm burden reductions (WBRs) were compared between different treatment groups of R-and S-PZQ and the control group.

\section{Methods}

\section{Drugs, media and animals}

Pure analytes, R-, S- and trans-4-OH-PZQ were kindly supplied by Merck (Darmstadt, Germany). Racemic PZQ was purchased from Sigma Aldrich (Buchs, Switzerland). Drugs for in vitro studies were dissolved in dimethyl sulfoxide (DMSO; Fluka, Buchs, Switzerland). A mixture of $7 \%$ (vol/vol) Tween 80 and 3\% ethanol (vol/vol) was used to suspend the drugs for in vivo treatment.

For cultivating adult schistosomes, standard RPMI 1640 medium (Life Technologies, Carlsbad, CA, USA) with addition of $5 \%$ heat-inactivated foetal calf serum (iFCS), $100 \mathrm{U} / \mathrm{ml}$ of penicillin (Life Technologies) and $100 \mu \mathrm{g} / \mathrm{ml}$ of streptomycin (Life Technologies) was used.

Thirty LVG golden Syrian hamsters (male, weight approximately $150 \mathrm{~g}$ ), infected with approximately 350 cercariae of S. haematobium each, were obtained from the biomedical research institute (NR-21966, Rockville, MD, USA). The animals were kept under controlled conditions $\left(22{ }^{\circ} \mathrm{C}, 50 \%\right.$ humidity, $12 / 24$ h of light and free access to water and rodent diet) to allow development of chronic infection 3 months post-exposure.

\section{In vitro and in vivo studies \\ In vitro studies}

Adult worms were tested at a range of $0.01-3.00 \mu \mathrm{g} / \mathrm{ml}$ for R-PZQ and PZQ, at $0.1-30.0 \mu \mathrm{g} / \mathrm{ml}$ for $\mathrm{S}-\mathrm{PZQ}$ and $0.1-3.0 \mu \mathrm{g} / \mathrm{ml}$ for trans-4-OH-PZQ. Drugs were prepared in medium using serial dilutions in flat bottom 24-well plates (BD, Falcon, Corning, NY, USA). Control wells consisted of $0.3 \%$ DMSO, which was the highest concentration of DMSO used to dissolve the drugs. Three months post-infection, S. haematobium-infected hamsters were euthanized with $\mathrm{CO}_{2}$ and dissected. Adult worms were collected from hepatic portal and mesenteric veins. Two to three worms, sexes equally represented, were placed per well and each concentration of the drug was tested in duplicates. Worms were incubated at $37{ }^{\circ} \mathrm{C}$ and $5 \% \mathrm{CO}_{2}$ and the phenotypic changes were evaluated $1,4,24,48$ and $72 \mathrm{~h}$ post-incubation using a motility scale ranging from 3 (normal activity) to 0 (no activity, granularity present).

$\mathrm{IC}_{50}$ values were calculated with CompuSyn ${ }^{\oplus}$ software (version 1.0) from motility values at different concentrations of each drug. The linear correlation coefficient ( $r$ value) reflects the conformity of the experimental data. The eudysmic ratio was calculated using the following formula: $\mathrm{IC}_{50}$ distomer/ $\mathrm{IC}_{50}$ eutomer, where $\mathrm{R}-\mathrm{PZQ}$ is the eutomer and S-PZQ the distomer.

\section{In vivo studies}

Infected S. haematobium hamsters in groups of 3-4 were treated 3 months post-infection with a single oral dose of $250.0 \mathrm{mg} / \mathrm{kg} \mathrm{PZQ}, 125.0 \mathrm{mg} / \mathrm{kg} \mathrm{R}-\mathrm{PZQ}, 62.5 \mathrm{mg} / \mathrm{kg}$ 
R-PZQ, $31.0 \quad \mathrm{mg} / \mathrm{kg} \quad \mathrm{R}-\mathrm{PZQ}, \quad 500.0 \quad \mathrm{mg} / \mathrm{kg} \quad \mathrm{S}-\mathrm{PZQ}$, $250.0 \mathrm{mg} / \mathrm{kg} \mathrm{S}-\mathrm{PZQ}$ or $125.0 \mathrm{mg} / \mathrm{kg} \mathrm{S}-\mathrm{PZQ} .10$ days posttreatment hamsters were euthanized with $\mathrm{CO}_{2}$ and dissected. Adult worms from intestinal veins were counted and sexed and the liver was inspected for live/dead worms and eggs. The control group (untreated) was dissected at the same time and the mean worm burden of treated hamsters was compared with untreated hamsters to determine the WBR. $\mathrm{ED}_{50}$ and eudysmic ratios were calculated as described above.

\section{Statistics}

Statistical tests were performed using Prism software (version 7.03, GraphPad, CA, USA). Unpaired t-test allowing for unequal variances was used to determine differences in worm burden between the control group and the treatment groups. $P<0.05$ was considered to be significant.

\section{Results}

\section{In vitro studies}

In vitro $\mathrm{IC}_{50}$ and $\mathrm{IC}_{90}$ values ( 4 and $72 \mathrm{~h}$ of incubation) of racemic $\mathrm{PZQ}$, pure enantiomers and trans-4-OHPZQ obtained against adult worms of S. haematobium are summarised in Table 1 . The $\mathrm{IC}_{50}$ of $\mathrm{R}-\mathrm{PZQ}$ was $0.007 \mu \mathrm{g} / \mathrm{ml}$ at $4 \mathrm{~h}$ and $0.01 \mu \mathrm{g} / \mathrm{ml}$ at $72 \mathrm{~h}$, while S-PZQ was $501 \times$ less active (eudysmic ratio at $4 \mathrm{~h}$ ) yielding $\mathrm{IC}_{50}$ values of 3.51 and $3.40 \mu \mathrm{g} / \mathrm{ml}$ ( 4 and $72 \mathrm{~h}$, respectively). The $\mathrm{IC}_{50}$ of PZQ was $0.03 \mu \mathrm{g} / \mathrm{ml}$, which is $4.3 \times$ higher compared to R-PZQ. Trans-4-OH-PZQ revealed an $\mathrm{IC}_{50}$ of $1.47 \mu \mathrm{g} / \mathrm{ml}$ at 4 and $72 \mathrm{~h}$, respectively.

\section{In vivo studies}

Total WBRs and female WBRs following different single oral doses of R-, S-PZQ and PZQ are presented in Table 2. For all drugs and dosages tested, a higher activity on the female worms was observed. PZQ reduced the total worm burden by $99.3 \%$ at a single dose of $250.0 \mathrm{mg} / \mathrm{kg}$. R-PZQ showed the highest total WBR at $125.0 \mathrm{mg} / \mathrm{kg}(98.5 \%)$ while with a half of the dose $(62.5 \mathrm{mg} / \mathrm{kg})$ the WBR was lower (75.6\%). The lowest dose of R-PZQ, $31.0 \mathrm{mg} / \mathrm{kg}$, yielded still a high total WBR of $73.3 \%$. S-PZQ revealed a high activity at 500.0 and $250.0 \mathrm{mg} / \mathrm{kg}$ with total WBRs of 94.1 and $83.0 \%$. A moderate total WBR of $46.7 \%$ was observed when the hamsters were treated with $125.0 \mathrm{mg} / \mathrm{kg}$ of S-PZQ. The calculated $\mathrm{ED}_{50} \mathrm{~s}$ for $\mathrm{R}$ - and S-PZQ were 24.7 and $127.6 \mathrm{mg} / \mathrm{kg}$, respectively, with a corresponding eudysmic ratio of 5.17. All female and total WBRs of the different treatment groups were significantly different from the control group $(P<0.05)$, except for the total WBRs of lowest doses of R- and S-PZQ (31.0 $\mathrm{mg} / \mathrm{kg}$ and $125.0 \mathrm{mg} / \mathrm{kg}$, respectively), which showed not to be significantly better compared to the control group.

\section{Discussion}

With no available alternative drug, PZQ is the mainstay of schistosomiasis control [9-12]. Apart from reliance on a single drug, an additional drawback is the large dose required, resulting in a huge size of the tablet, containing a racemic mixture of PZQ [31-33]. The discussion about the activity of each enantiomer of the drug, namely R- and S-PZQ, has been on-going and therefore it is time to conclude which enantiomer is responsible for the antischistosomal activity [9, 32-34]. Moreover, development of a paediatric PZQ formulation is currently ongoing and thorough examination of in vitro and in vivo activity of PZQ and its enantiomers will not only contribute to a better understanding of the drug but also aid to select the optimal entity for the final formulation (R-PZQ or racemic PZQ) [35]. While S. mansoni has been thoroughly researched, $S$. haematobium remains neglected in the laboratory, despite of being responsible for a large share of the burden of schistosomiasis [26, 29]. This holds true also for drug sensitivity testing including studies on PZQ. While a few studies assesed the activity of PZQ on S. haematobium, all of them only evaluated the activity of racemic PZQ $[18,19,29]$. Studies on S. haematobium are pivotal as many antischistosomals, oxamniquine, metrifonate and PZQ have very distinct profiles on the different schistosome species [30]. To our knowledge, our study is the first to investigate the activity of both enantiomers of $\mathrm{PZQ}$, at three different doses, compared to a single dose of $\mathrm{PZQ}$, in vivo. Additionally, the activity of both enantiomers was compared also to the main human metabolite, trans-4-OH-PZQ, and the racemic drug, in vitro. Our results show that R-PZQ is driving the antischistosomal activity of $\mathrm{PZQ}$, both in vitro and in vivo. The $\mathrm{IC}_{50}$ value of racemic PZQ was $4.3 \times$ higher compared to the enantiopure R-PZQ in vitro. In vivo results followed a similar pattern: R-PZQ at $125 \mathrm{mg} / \mathrm{kg}$ resulted in WBRs above $98 \%$, as did a twice higher dose of PZQ, $250 \mathrm{mg} / \mathrm{kg}$. The latter result is in the line with findings from the dose-

Table $1 \mathrm{IC}_{50}$ and IC 90 values of PZQ, R-PZQ, S-PZQ enantiomers and trans-4-OH-PZQ against adult worms of S. haematobium

\begin{tabular}{llllllll}
\hline & $I_{50}$ at $4 \mathrm{~h}(\mu \mathrm{g} / \mathrm{ml})$ & $r$-value & $I_{50}$ at $72 \mathrm{~h}(\mu \mathrm{g} / \mathrm{ml})$ & r-value & $I_{90}$ at $72 \mathrm{~h}(\mu \mathrm{g} / \mathrm{ml})$ & r-value & Eudysmic ratio \\
\hline PZQ & 0.03 & 0.978 & 0.03 & 0.965 & 0.09 & 0.978 & 0.940 \\
R-PZQ & 0.007 & 0.803 & 0.01 & 0.940 & 0.03 & 0.923 \\
S-PZQ & 3.51 & 0.925 & 3.40 & 0.923 & 5.98 & 0.891 \\
Trans-4-OH-PZQ & 1.47 & 0.891 & 1.47 & 0.891 & 3.31 & \\
\hline
\end{tabular}


Table 2 Worm burden reductions (WBRs) following different single oral doses of R, S-PZQ and PZQ

\begin{tabular}{|c|c|c|c|c|c|c|c|c|c|}
\hline & \multirow{2}{*}{$\begin{array}{l}\text { No. of hamsters } \\
\text { cured/treated }\end{array}$} & \multicolumn{4}{|c|}{ Mean no. of alive worms \pm SD } & \multirow{2}{*}{$\begin{array}{l}\text { WBR } \\
\text { (\%) }\end{array}$} & \multirow{2}{*}{$\begin{array}{l}\text { Female } \\
\text { WBR (\%) }\end{array}$} & \multirow{2}{*}{$\begin{array}{l}\mathrm{ED}_{50} \\
(\mathrm{mg} / \mathrm{kg})\end{array}$} & \\
\hline & & Liver & Mesenteric veins & Total & Females & & & & \\
\hline Control & $0 / 4$ & $2.75 \pm 3.8$ & $31.0 \pm 9.5$ & $33.8 \pm 16.8$ & $15.3 \pm 5.2$ & - & - & - & \\
\hline \multicolumn{10}{|l|}{ PZQ } \\
\hline $250.0 \mathrm{mg} / \mathrm{kg}$ & $3 / 4$ & $0.25 \pm 0.5$ & 0 & $0.3 \pm 0.5$ & 0 & 99.3 & 100 & & \\
\hline $200.0 \mathrm{mg} / \mathrm{kg}^{\mathrm{b}}$ & & & & & & 77.2 & & 118.1 & \\
\hline $150.0 \mathrm{mg} / \mathrm{kg}^{\mathrm{b}}$ & & & & & & 66.1 & & & \\
\hline $100.0 \mathrm{mg} / \mathrm{kg}^{\mathrm{b}}$ & & & & & & 39.2 & & & \\
\hline \multicolumn{10}{|l|}{ R-PZQ } \\
\hline $125.0 \mathrm{mg} / \mathrm{kg}$ & $2 / 4$ & $0.25 \pm 0.5$ & $0.25 \pm 0.5$ & $0.5 \pm 0.6$ & 0 & 98.5 & 100 & $24.7^{\mathrm{a}}$ & \\
\hline $62.5 \mathrm{mg} / \mathrm{kg}$ & $1 / 4$ & $5.0 \pm 4.7$ & $3.25 \pm 3.6$ & $8.3 \pm 8.1$ & $2.3 \pm 3.3$ & 75.6 & 85.2 & & \\
\hline $31.0 \mathrm{mg} / \mathrm{kg}$ & $0 / 3$ & $6.7 \pm 11.5$ & $2.3 \pm 2.3$ & $9.0 \pm 13.9$ & $4.0 \pm 6.9$ & 73.3 & 73.8 & & \\
\hline \multicolumn{10}{|l|}{ S-PZQ } \\
\hline $500.0 \mathrm{mg} / \mathrm{kg}$ & $3 / 4$ & $1.25 \pm 2.5$ & $0.75 \pm 1.5$ & $2.0 \pm 4.0$ & 0 & 94.1 & 100 & $127.6^{a}$ & $5.17^{c}$ \\
\hline $250.0 \mathrm{mg} / \mathrm{kg}$ & $2 / 4$ & $4.0 \pm 4.9$ & $1.75 \pm 2.1$ & $5.8 \pm 6.9$ & 0 & 83.0 & 100 & & \\
\hline $125.0 \mathrm{mg} / \mathrm{kg}$ & $0 / 3$ & $7.0 \pm 6.2$ & $11.0 \pm 6.0$ & $18.0 \pm 12.1$ & $0.7 \pm 0.6$ & 46.7 & 95.6 & & \\
\hline
\end{tabular}

Determined on total worm burden reductions

${ }^{\mathrm{b}}$ Data reported by Webbe \& James [18]

'Eudysmic ratio

response relationship study with PZQ in S. haematobium infected hamsters conducted by Webbe \& James, yielding an $\mathrm{ED}_{50}$ of $118 \mathrm{mg} / \mathrm{kg}$ [18].

Strikingly, it seems that in case of $S$. haematobium in contrast to S. mansoni [36], also S-PZQ possesses nonnegligible activity. An $\mathrm{ED}_{50}$ of $127.6 \mathrm{mg} / \mathrm{kg}$ was calculated for S-PZQ, which is close to the value of the racemic drug. For comparison, $S$. mansoni-infected mice treated with $800 \mathrm{mg} / \mathrm{kg} \mathrm{S-PZQ} \mathrm{showed} \mathrm{only} \mathrm{a} \mathrm{low} \mathrm{WBR}$ of $19.6 \%$. Hence, the eudysmic ratio is 64-fold lower for $S$. haematobium compared to S. mansoni [36]. However, it is worth highlighting that differences in the drug sensitivity between the two species might also be due to differences in the model, the hamster versus mouse model [27]. Finally, also trans-4-OH-PZQ revealed a 2.3 and 2.4-fold higher activity (72 and $4 \mathrm{~h}$, respectively) against S. haematobium in vitro when compared to S. mansoni. A contribution of S-PZQ and trans-4-OH-PZQ to PZQ's activity could explain the higher sensitivity to PZQ of $S$. haematobium when compared to $S$. mansoni in humans [30]. In humans, S. haematobium are residing in the venus plexus of the bladder, getting exposed mostly to high concentrations of S-PZQ and the metabolite, as a consequence of first pass metabolism. This is in contrast to S. mansoni, where the adult worms are exposed to un-metabolised drug in the mesenteric veins, prior to reaching the liver.

In addition, we observed increased sensitivity of female worms compared to the males in vivo for all entities studies. For example, the lowest dose of S-PZQ achieved a female WBR of 95.6\%, while the males were only mildly affected (total WBR of 46.7\%). The higher activity of PZQ on female worms has been reported previously [20].

As mentioned above, due to the difficulties maintaining the $S$. haematobium life-cycle, our in vivo data are based on a single experiment and the in vitro data on duplicate experiments. While we feel our data are robust and in line with standard procedures, in order to draw a final conclusion, which PZQ enantiomer to recommend for the therapy of $S$. haematobium infections, additional experiments would be beneficial.

\section{Conclusion}

To conclude, we observed that R-PZQ possesses the highest activity among the PZQ enantiomers and main human metabolite tested against $S$. haematobium. Surprisingly, S-PZQ- showed a high activity in vivo. Additionally, the main human metabolite displayed an activity higher than S-PZQ in vitro. In the line with the current efforts to develop a paediatric formulation, an enantioselective R-PZQ formulation might bear some risk; however, further laboratory studies as well as clinical trials, including pharmacokinetic/pharmacodynamics relationship studies, would be required to confirm our findings.

\section{Abbreviations}

$\mathrm{ED}_{50}$ : Dose of the drug needed to reduce the worm burden by $50 \%$; $\mathrm{IC}_{50}$ : Concentration of the drug, needed to kill $50 \%$ of the parasites; PZQ: Praziquantel; WBR: Worm burden reduction 


\section{Acknowledgements}

We would like to thank Biomedical Research Institute (Rockville, MD) for providing infected animals and to Fadri Christoffel for assistance with animal work. We are grateful to Merck for providing R-, S- and trans-4-OH-PZO.

\section{Funding}

We are grateful to the European Research Council (ERC-2013-CoG 614,739A HERO) for financial support. The funders had no role in design, in the collection, analysis, and interpretation of data; in the writing of the manuscript; and in the decision to submit the manuscript for publication.

\section{Availability of data and materials}

The datasets supporting the conclusions of this article are included within the article.

\section{Authors' contributions}

JK and JKo designed the experiment. MV and JKo performed the experiments. The statistics and the manuscript were prepared by JKo. All authors read and approved the final manuscript.

\section{Ethics approval}

The current study was approved by the local veterinary agency based on Swiss cantonal and national regulations (permission no. 2070).

\section{Consent for publication}

Not applicable.

\section{Competing interests}

The authors declare that they have no competing interests.

\section{Publisher's Note}

Springer Nature remains neutral with regard to jurisdictional claims in published maps and institutional affiliations.

Received: 12 April 2017 Accepted: 13 July 2017

Published online: 01 August 2017

\section{References}

1. Steinmann P, Keiser J, Bos R, Tanner M, Utzinger J. Schistosomiasis and water resources development: systematic review, meta-analysis, and estimates of people at risk. Lancet Infect Dis. 2006;6(7):411-25.

2. Utzinger J, Raso G, Brooker S, De Savigny D, Tanner M, Ornbjerg N, et al. Schistosomiasis and neglected tropical diseases: towards integrated and sustainable control and a word of caution. Parasitology. 2009;136(13):1859-74

3. Colley DG, Bustinduy AL, Secor WE, King CH. Human schistosomiasis. Lancet. 2014;383(9936):2253-64.

4. Gryseels B, Polman K, Clerinx J, Kestens L. Human schistosomiasis. Lancet. 2006;368(9541):1106-18.

5. Ismail HAHA, Hong S-T, Babiker ATEB, Hassan RMAE, Sulaiman MAZ, Jeong H$\mathrm{G}$, et al. Prevalence, risk factors, and clinical manifestations of schistosomiasis among school children in the White Nile River basin. Sudan Parasit Vectors. 2014;7(1):478.

6. Ross AGP, Bartley PB, Sleigh AC, Olds GR, Li Y, Williams GM, et al. Schistosomiasis; Current concepts. N Engl J Med. 2002;346(16):1212-20.

7. King $\mathrm{CH}$, Dangerfield-cha $\mathrm{M}$. The unacknowledged impact of chronic schistosomiasis. Chronic IIIn. 2008:4:65-79.

8. Bustinduy AL, Wright S, Joekes EC, Kabatereine NB, Reinhard-Rupp J, King $\mathrm{CH}$, et al. One hundred years of neglect in paediatric schistosomiasis. Parasitology. 2017:1-11.

9. Cioli D, Pica-Mattoccia L, Basso A, Guidi A. Schistosomiasis control: Praziquantel forever? Mol Biochem Parasitol. 2014;195(1):23-9.

10. Keiser J, Utzinger J. The drugs we have and the drugs we need against major helminth infections. Adv Parasitol. 2010;73(10):197-230.

11. Olliaro P, Delgado-Romero P, Keiser J. The little we know about the pharmacokinetics and pharmacodynamics of praziquantel (racemate and Renantiomer). J Antimicrob Chemother. 2014;69:863-70

12. Utzinger J, Keiser J. Schistosomiasis and soil- transmitted helminthiasis: common drugs for treatment and control. Expert Opin Drug Discov. 2004;5:263-85.

13. Geary TG. Are new anthelmintics needed to eliminate human helminthiases? Curr Opin Infect Dis. 2012;25(6):709-17.
14. Melman SD, Steinauer ML, Cunningham C, Kubatko LS, Ibrahim N, Wynn NB, et al. Reduced susceptibility to praziquantel among naturally occurring Kenyan isolates of Schistosoma mansoni. PLoS Negl Trop Dis. 2009;3(8) doi:10.1371/journal.pntd.0000504.

15. Liang Y, Coles GC, Doenhoff MJ, Southgate VR. In vitro responses of praziquantel-resistant and -susceptible Schistosoma mansoni to praziquantel. Int J Parasitol. 2001;31:1227-35.

16. Xiao SH, Catto BA, Webster LTJ. Effects of praziquantel on different developmental stages of Schistosoma mansoni in vitro and in vivo. J Infect Dis. 1985;151(6):1130-7.

17. Chavasse CJ, Brown MC, Bell DR. Schistosoma mansoni: Activity responses in vitro to praziquantel. Z Parasitenkd. 1979;58:169-74.

18. Webbe G, James C. A comparison of the susceptibility to praziquantel of Schistosoma haematobium, S. japonicum, S. mansoni, S. intercalatum and S. mattheei in hamsters. Z Parasitenkd. 1977:52:169-77.

19. Botros SS, Hammam OA, El-Lakkani NM, El-Din SH, Ebeid FA. Schistosoma haematobium (Egyptian strain): rate of development and effect of praziquantel treatment. J Parasitol. 2008;94(2):386-94.

20. Pica-Mattoccia L, Cioli D. Sex- and stage-related sensitivity of Schistosoma mansoni to in vivo and in vitro praziquantel treatment. Int J Parasitol. 2004;34:527-33.

21. Tanaka M, Ohmae H, Utsunomiya H, Nara T, Irie Y, Yasuraoka K. A comparison of the antischistosomal effect of levo- and dextro- praziquantel on Schistosoma japonicum and S. mansoni in mice. Am J Trop Med Hyg. 1989;41(2):198-203.

22. Xiao SH, Catto BA. Comparative in vitro and in vivo activity of racemic praziquantel and its levorotated isomer on Schistosoma mansoni. J Infect Dis. 1989;159(3):589-92.

23. Xiao SH, Chollet J, Booth M, Weiss NA, Tanner M. Therapeutic effect of praziquantel enantiomers in mice infected with Schistosoma mansoni. Trans R Soc Trop Med Hyg. 1999;93:324-5.

24. Staudt U, Schmahl G, Blaschke G, Mehlhorn H. Light and scanning electron microscopy studies on the effects of the enantiomers of praziquantel and its main metabolite on Schistosoma mansoni in vitro. Parasitol Res, 1992:78:392-7.

25. Xiao SH, You JQ, Guo HF, Catto BA. Uptake and effect of praziquantel and the major human oxidative metabolite, 4-hydroxypraziquantel, by Schistosoma japonicum. J Infect Dis. 1991;77(2):241-5.

26. Keiser J. In vitro and in vivo trematode models for chemotherapeutic studies. Parasitology. 2010;137:589-603.

27. Moore DV, Meleney HE. Comparative susceptibility of common laboratory animals to experimental infection with Schistosoma haematobium. J Parasitol. 1954:40(4):392-7.

28. Doenhoff MJ, Hagan P, Cioli D, Southgate V, Pica-Mattoccia L, Botros S, et al. Praziquantel: its use in control of schistosomiasis in sub-Saharan Africa and current research needs. Parasitology. 2009:136:1825-35.

29. Botros S, Pica-Mattoccia L, William S, El-Lakkani N, Cioli D. Effect of praziquantel on the immature stages of Schistosoma haematobium. Int J Parasitol. 2005;35:1453-7.

30. Zwang J, Olliaro PL. Clinical efficacy and tolerability of praziquantel for intestinal and urinary schistosomiasis - a meta-analysis of comparative and non-comparative clinical trials. PLoS Negl Trop Dis. 2014:8(11):e3286.

31. Geary TG, Woo K, McCarthy JS, Mackenzie CD, Horton J, Prichard RK, et al. Unresolved issues in anthelmintic pharmacology for helminthiases of humans. Int J Parasitol. 2010;40(1):1-13.

32. Doenhoff MJ, Cioli D, Utzinger J. Praziquantel: mechanisms of action, resistance and new derivatives for schistosomiasis. Curr Opin Infect Dis. 2008;21(6):659-67.

33. Meyer T, Sekljic H, Fuchs S, Bothe H, Schollmeyer D, Miculka C. Taste, a new incentive to switch to (R)-praziquantel in schistosomiasis treatment. PLoS Negl Trop Dis. 2009:3(1):3-7.

34. Bustinduy AL, Waterhouse D, de Sousa-Figueiredo JC, Roberts SA, Atuhaire A, Van Dam GJ, et al. Population pharmacokinetics and pharmacodynamics of praziquantel in Ugandan children with intestinal schistosomiasis: higher dosages are required for maximal efficacy. MBio. 2016;7(4):e00227-16.

35. Betson M, Stothard JR, Bustinduy A, Reinhard-rupp J. Schistosomiasis in African infants and preschool children : let them now be treated! Trends Parasitol. 2013:29(4):197-205.

36. Meister I, Ingram-Sieber K, Cowan N, Todd M, Robertson MN, Meli C, et al. Activity of praziquantel enantiomers and main metabolites against Schistosoma mansoni. Antimicrob Agents Chemother. 2014;58(9):5466-72. 